\title{
"EU NUM MATEI UM MONTE DE GENTE E CHEGUEI AGORA E PEDI 'SEM VIOLÊNCIA " " - CONSTRUÇÕES IDENTITÁRIAS DE UM MANIFESTANTE FRENTE ÀS AÇÕES DA POLÍCIA NOS PROTESTOS DE 2013 NO RIO DE JANEIRO ${ }^{1}$
}

Etyelle Pinheiro de Araújo, formada em Licenciatura Plena em História pela Faculdade de Filosofia Santa Doroteia, pós-graduada em Educação e Contemporaneidade pelo CEFET-Unde Nova Friburgo, atualmente é mestranda em Estudos da Linguagem pela PUC-Rio Email: etyelle.araujo@gmail.com

\section{Resumo}

Partindo do contexto das manifestações de junho de 2013, no Rio de Janeiro, este artigo objetiva estudar a forma como os manifestantes constroem significados acerca da violência praticada pela polícia nos protestos e como esses significados colaboram para a construção identitária desses indivíduos como ativistas. $\mathrm{O}$ artigo observa, mais especificamente, $\mathrm{o}$ caráter dialógico e polifônico dos discursos, bem como a natureza sociointeracional da entrevista.

\begin{abstract}
Based on the context of the demonstrations of june, 2013 in Rio de Janeiro, this article aims to study the way in which the protestors construct/build meaning about the violence practiced by the police during the protests and how those meanings collaborate with the identity constructions of these individuals as activists. Observing the dialogic and polyphonic character of the discourse, as well as the socio-interactional nature of the interview.
\end{abstract}

\section{Introdução}

A partir de 2010, diversos protestos populares, que questionavam o regime político vigente, fazendo uso da internet como forma de divulgação, aconteceram em vários países, em função de diversos problemas da sociedade. No Brasil, a partir do aumento das tarifas de transporte coletivo, milhões de brasileiros foram às ruas protestar. $\mathrm{O}$ movimento tomou proporções maiores e a causa adquiriu não apenas a reivindicação contra o aumento da tarifa de transporte coletivo, mas a indignação contra a corrupção e o questionamento da qualidade dos serviços públicos.

Apesar do caráter pacífico das manifestações, ao menos quando se iniciavam, elas, em sua maioria, terminavam em violentos confrontos entre a polícia e os manifestantes. Partindo disso, surge a problemática: Como os manifestantes constroem significados acerca da violência da polícia nos protestos? De que forma esses significados colaboram para a construção identitária desses manifestantes como ativistas?

Em busca de tais entendimentos, esta pesquisa desenvolveu-se observando que a forma como os indivíduos significam determinadas situações por meio do discurso nas interações sociais das quais participam (Schiffrin, 1994), bem como constroem suas identidades, está intimamente ligada ao contexto nos quais tais interações se dão (Moita Lopes, 2003) e levam em consideração o caráter constitutivo, dialógico e polifônico do discurso (Bakhtin, 1997; 2003). Posto isso, o presente artigo busca, por meio de uma metodologia qualitativa interpretativista, analisar a interação construída entre eu (a pesquisadora) e um manifestante em uma situação de entrevista, observando, também as peculiaridades desse tipo de situação (Mishler, 1986). A pesquisa tem uma inspiração na auto-etnografia, tendo em vista, o fato de eu, a pesquisadora, ser participante do mesmo contexto que pesquiso.

\footnotetext{
${ }^{1}$ Este artigo foi apresentado no Seminário de Estudos do Discurso em novembro de 2014 na Universidade Federal da Bahia (UFBA) e comporá os anais do evento, que serão disponibilizados futuramente em: http://www.sedisufba2014.ufba.br/ 
A análise dos dados gerados possibilitou entendimentos acerca da forma como os manifestantes constroem suas identidades como ativistas, frente às ações repressoras da polícia, demonstrando que tal construção ocorre de forma situada (no caso desta pesquisa, na entrevista), levando em consideração o contexto (macro- das manifestações), contando, ainda, com a presença de diversas outras vozes (como a da mídia) no discurso dos ativistas.

\section{1) Contexto Histórico}

O ciclo de manifestações ocorrido no Brasil, em 2013, ficou conhecido como Jornadas de Junho e teve como pauta principal, a reinvindicação pela diminuição da tarifa de transporte coletivo. Os protestos iniciaram-se nas capitais e espalharam-se por diversas cidades do interior. À medida que se espalhavam, as reinvindicações também aumentavam. O movimento foi se delineando sem nomes, sem partidos, sem lideranças, assumindo caráter diferente daqueles historicamente constituídos no Brasil. Sendo propagado por meio das redes sociais.

Sobre esses aspectos, Castells (2012) ressalta a semelhança entre os diversos movimentos de protesto surgidos em distintas partes do mundo, ainda que sob circunstâncias históricas, culturais, econômicas e políticas distintas. Na maioria desses movimentos, é possível identificar alguns elementos comuns, como o uso das redes sociais, das ocupações do espaço público, da busca por uma horizontalidade. Ainda que com ideias confusas com relação a um projeto ideológico claro, dado a desconfiança e o descontentamento com as formas de governo conhecidas, os indivíduos participantes de movimentos desse tipo expressam a crise da representatividade que vem suscitando questionamentos acerca dos fundamentos dos regimes democráticos.

Os protestos, normalmente, iniciavam-se de forma pacífica, inclusive com o slogan "sem violência" e terminavam com confronto. Ora iniciado pela tentativa dos policiais de dispersar a manifestação, ora por tentativa de depredação de algum patrimônio por parte de alguns grupos de manifestantes. O pico das manifestações deu-se no dia 20 de junho, quando em centenas de cidades pelo Brasil, milhares de brasileiros foram às ruas protestar, não apenas nos grandes centros, mas em cidades espalhadas pelo interior também. Neste dia, no Rio de Janeiro, a manifestação seguiu de forma pacífica em direção à prefeitura da cidade. Pouco antes da chegada ao local, iniciou-se um confronto entre policiais e alguns manifestantes. Após isso, algumas pessoas permaneceram ali, tentando resistir, revidando a violência, outras tentaram retornar pelo caminho que fizeram. Entretanto, muitos que ali estavam, de forma pacífica, sofreram com os atos de repressão extremamente violentos por parte da Polícia Militar. O uso indiscriminado de bombas de gás lacrimogêneo, spray de pimenta e balas de borracha, atingiu a todos que participavam da manifestação, ou que simplesmente passavam pelo local. Mesmo depois de dispersa a multidão, pelas ruas do Centro ainda se ouvia os disparos de tiros de bala de borracha e bombas de gás. A cena desenhada era de perseguição. Diversos coletivos e partidos políticos emitiram notas de repúdio à repressão da polícia depois desse episódio. 
Após esse dia, ocorreu um expressivo esvaziamento das ruas, embora os protestos pela cidade do Rio não tivessem se encerrado. O preço da passagem baixou. Vitória do movimento. No entanto, as reivindicações haviam alcançado (ao menos nos cartazes carregados pelos manifestantes) uma esfera acima da luta pela diminuição da tarifa de transporte e ainda assim, as ruas se esvaziaram. Qual seria o motivo desse esvaziamento se 'a luta continua'? Uma possível leitura seria o medo advindo da grande repressão policial que acabou gerando uma escalada de violência. Com o aumento da repressão, grupos de resistência foram surgindo e sob os rostos cobertos, revidavam a violência ${ }^{2}$. Apesar de vazios, os protestos não cessaram, assim como a repressão violenta. Uma outra leitura que circulou por meio da mídia corporativa e que se espalhou pelas redes sociais, foi que, em função da multiplicidade de reivindicações, o movimento havia perdido o foco.

Com a diminuição da participação popular nos protestos, grupos distintos de manifestantes passaram a atuar de formas diversas em protesto contra o governo, não apenas no Rio de Janeiro, mas em várias cidades do país, configurando-se como ativistas. Tal situação torna-se relevante para esse estudo, tendo em vista que esses grupos passam a interagir, construindo um novo contexto e novos significados acerca de suas atuações nas ruas $^{3}$ - mantendo as reinvindicações que estiveram em pauta durante as manifestações de junho e outras mais que foram surgindo.

Importante, ainda, se faz mapear o perfil desses manifestantes, levando em consideração que durante a insurgência do movimento, a composição de quem estava nas ruas foi questão amplamente discutida pela mídia corporativa, assim como por intelectuais, que, a partir do entendimento de quem seriam essas pessoas, buscavam entender quais seus propósitos num levante popular de características tão peculiares, se comparados aos movimentos anteriores. O Data Folha publicou, no dia 21 de junho de 2013, uma pesquisa com o intuito de apurar a renda média dos manifestantes de São Paulo e suas posições ideológicas ${ }^{4}$. Na cidade de Belo Horizonte, o Instituto Innovare realizou uma pesquisa semelhante $^{5}$, publicada no dia 23 de junho. Já na cidade do Rio de Janeiro, a Clave de Fá Pesquisas e Projetos contratou três empresas e divulgou, por meio da Band News os resultados de uma pesquisa realizada durante a passeata de 20 de junho ${ }^{6}$.

A pesquisa realizada no Rio de Janeiro aponta para composição de maioria jovem, presente na referida manifestação, trabalhadores, em grande parte. Diferente do que a grande mídia vinha divulgando, que afirmava serem jovens estudantes, oriundos da classe média ${ }^{7}$. Em recente artigo publicado, André Singer (2013) discute a composição dos manifestantes de

\footnotetext{
${ }^{2}$ Grupos de resistência que praticavam a tática Black Bloc de cunho anarquista.

${ }^{3}$ Tal questão será melhor explicitada no item 3.1 Dados etnográficos.

${ }^{4}$ Disponível em:

http://search.folha.com.br/search?q=perfi1\%20dos\%20manifestantes\&site=datafolha\&skin=datafolha Acesso em 16/06/2014.

${ }^{5}$ Disponível em: http://www.innovarepesquisa.com.br/blog/quem-e-e-o-que-pensa-o-manifestante-de-belo-horizonte/ Acesso em> 16/06/2014.

6 Disponível em: http://www.clavedefapp.com.br/portfolio/perfil-dos-manifestantes-do-rio-de-janeiro/ Acesso em: 13/06/2014

${ }^{7} \mathrm{O}$ termo classe média é passível de discussão, pois no Brasil os padrões do que seria classe alta, média ou baixa veem se transformando ao longo dos anos.
} 
junho e afirma que ali estavam presentes tanto uma classe média tradicional, inconformada com diferentes aspectos da realidade nacional, quanto o que ele denomina novo proletariado, que se configura nos trabalhadores, em geral jovens, que conseguiram emprego com carteira assinada na década lulista (2003-2013), mas que padecem com baixa remuneração, alta rotatividade e más condições de trabalho. Para este autor, os protestos do período estudado são reflexos das insatisfações desses dois grupos. Tal entendimento expressa a heterogeneidade dos grupos presentes no movimento, o que colabora para uma amplitude de reivindicações.

Ademais, é preciso observar também que o discurso que concebe os manifestantes de junho de 2013 como pertencentes a uma classe média colabora para a diminuição da importância/legitimidade das manifestações, uma vez que se elas seriam conduzidas por um grupo privilegiado, não seria um movimento de minorias, de "proletariado". Sendo assim, não se caracterizaria como uma luta legítima, de pessoas que realmente precisariam reivindicar seus direitos.

A partir da situação aqui exposta, nasce a problemática: como os manifestantes constroem significados acerca da violência da polícia nos protestos? De que forma esses significados colaboram para a construção identitária desses manifestantes, como ativistas? Para o entendimento dessas duas questões levantadas acima, é preciso observar a forma como os indivíduos constroem significados, levando em consideração que essa construção se dá na interação social.

\section{2) Aspectos Metodológicos}

Para o desenvolvimentos deste artigo, alinhamo-nos a uma metodologia qualitativa interpretativa (Denzin e Lincoln, 2000), buscando entendimentos a respeito de como as formas de organizações da sociedade relacionam-se com as atividades dos indivíduos no processo de fazer escolhas e de conduzir a ação social em conjunto, partindo da ideia de que uma das principais tarefas de um pesquisador é a de tentar compreender o significado das ações humanas e o que as pessoas estão fazendo ao utilizarem a linguagem.

Dentro de uma perspectiva interpretativista, este trabalho ainda conta com a observação participante. Levando em consideração que eu, enquanto pesquisadora, participei do contexto em estudo, se faz extremamente necessário compreender que o saber produzido nesse tipo de pesquisa será permeado pela subjetividade do pesquisador, no caso, a minha. Como parte do campo em estudo, sobre ele exerço influência e por ele sou influenciada, torno-me, assim, parte da investigação, o que desestabiliza as noções de neutralidade ${ }^{8}$ em uma pesquisa. Com isso, a produção do conhecimento sobre a sociedade passa a ser concebida como objetivamente relativa, mais ou menos ideológica e sempre interpretativa (Velho, 2008 [1981]).

\footnotetext{
${ }^{8}$ Questão já muito discutida nos estudos em Ciências Humanas. Uma vez que o pesquisador escolhe algum determinado caso para estudo, ele delimita esse objeto, assim, manter a distância desse objeto para se alcançar resultados genuínos, neutros, livres de subjetividade torna-se uma questão inviável, já que o pesquisador, inevitavelmente faz parte de sua pesquisa. 
Para entendimento de como os significados foram construídos por meio do discurso entre os participantes da pesquisa, no caso, entre Rodrigo e eu, em função do contexto do qual fazem parte, faz-se importante a exposição de alguns dados etnográficos. Embora este estudo não se configure numa etnografia clássica, o fato de eu, a pesquisadora, participar do contexto investigado, possibilita a configuração da pesquisa nos moldes de uma auto-etnografia, quando o etnógrafo, ao pesquisar o outro, é envolvido na pesquisa de si próprio (Oliveira, 2012 apud Duarte \&Gomes, 2008) ${ }^{9}$.

\section{1) Dados etnográficos}

Após as manifestações de Junho, iniciou-se outro tipo de protesto. Em frente à casa do governador do Rio de Janeiro, Sérgio Cabral Filho, manifestantes montaram um acampamento que tinha como intenção pressionar o governador para que medidas fossem tomadas com relação à violência praticada pela polícia, melhorias na saúde e educação, além de outras reivindicações. Esse acampamento buscou ocupar o espaço público ${ }^{10}$ e recebeu o nome de "Ocupa Cabral".

Na mesma época, outros manifestantes iniciaram uma ocupação (interna, inicialmente) da Câmara Municipal do Rio de Janeiro, com a intenção de exigir que fosse realizada a CPI dos transportes públicos ${ }^{11}$. Passados alguns dias, os manifestantes foram retirados, de forma pacífica, de dentro do prédio e ainda permaneceram acampados em frente ao local por cerca de dois meses.

Nas duas ocupações, era comum a permanência de pessoas que apoiavam o movimento, ainda que não ficassem ali acampados. Era comum também a chegada de indivíduos pertencentes a diversas camadas da sociedade, interessados em conhecer do que se tratava o movimento. A permanência dessas pessoas no local colaborou para uma prática que se tornou comum: o debate acerca da política e da economia no país. As pessoas que nesses locais se achegavam, acabavam sendo envolvidas em conversas que traziam denúncias e questionavam as práticas políticas e econômicas, não apenas da cidade e do Estado do Rio de Janeiro, mas do país também. Dado o clima de revoltas que se espalhou por todo o país, a prática de ocupar o espaço público como forma de manifestação aconteceu em outras partes do país também. Eu, a pesquisadora, fui frequentadora desses locais e, como tal, participante dessas conversas espontâneas.

\footnotetext{
9 É possível ver o uso dessa metodologia em Oliveira (2012). Ao pesquisar como os alunos de uma escola da rede pública federal de ensino na Baixada Fluminense constroem valores e imagens de si por meio de padrões narrativos associados a um ethos que entende a educação formal como caminho para a ascensão social, a autora se torna parte da pesquisa, em função de sua inserção e íntima relação com o contexto pesquisado.

${ }^{10} \mathrm{~A}$ ocupação de espaços públicos tem desempenhado papel importante na história da mudança social por alguns motivos: cria-se na ocupação uma comunidade que se baseia na proximidade que auxilia na superação do medo de participar de um movimento social e confrontar a ordem dominante; há ali, a possibilidade de participar sem aderir à nenhuma ideologia; os espaços ocupados são sempre carregados do poder simbólico de invadir áreas do poder de Estado ou de instituições financeiras; por fim, as ocupações permitem a construção de uma comunidade livre num espaço simbólico, além da prática de assembleias soberanas nas quais todos ali podem recuperar seus direitos de representação (Castells, 2012).

${ }^{11}$ Para investigação dos contratos das empresas privadas de ônibus com a Prefeitura do Rio de Janeiro.
} 
Além dessas ocupações, surgiram diversos coletivos horizontalmente organizados ${ }^{12}$, que buscavam lutar pelas reivindicações que estiveram em pauta nas ruas (e por outras que foram surgindo), uns de forma mais cultural ${ }^{13}$ e outros como alternativas de mídia ${ }^{14}$.

A interação entre esses grupos - os coletivos organizados e os frequentadores das ocupações - construiu um novo contexto no qual os participantes interagiam, organizando diferentes formas de protestos, atuando como ativistas que lutavam de diversas formas por uma sociedade mais justa.

Num desses momentos de interação nas ocupações, fiz contato com Rodrigo (que também participava do contexto aqui explicitado) e explicando as minhas pretensões acadêmicas e, principalmente, a minha necessidade de buscar entendimentos sobre que significados os indivíduos estavam construindo sobre a violência que a polícia vinha aplicando durante as manifestações, solicitei a ele uma entrevista, em um caráter de bate-papo informal.

Os dados desta pesquisa foram, então, gerados por meio de uma entrevista semi estruturada com perguntas abertas e foram transcritos segundo o modelo de transcrição de Jefferson (cf. Lorder, 2008). A entrevista ocorreu no dia 05 de Outubro, após uma truculenta ação da polícia para a retirada forçada dos professores, que, naquele dia, estavam ocupando a parte interna da Câmara Municipal.

\section{3) Quadro Teórico}

\section{1) A entrevista como interação social}

$\mathrm{Na}$ sociedade, a todo momento estamos envolvidos em interações sociais ao nos relacionarmos com as outras pessoas. Essas interações contam não só com os indivíduos que dela participam, mas com o cenário (local em que acontecem) e com o propósito dessas interações (o motivo pelo qual as pessoas estão se relacionando umas com as outras).

Para buscar entendimentos sobre a forma como os indivíduos interagem numa sociedade e constroem significados, é preciso levar em consideração alguns aspectos importantes que fazem parte dessa interação. Goffman ([1964] 2002) convida-nos ao exame da situação social que, segundo ele, marca a relação entre a fala das pessoas e seus gestos com as suas atribuições sociais. Para Goffman, a situação social é definida como: “(...) um ambiente que proporciona possibilidades mútuas de monitoramento, qualquer lugar em que um indivíduo se encontra acessível aos sentidos nus de todos os outros que estão 'presentes', e para quem os outros indivíduos são acessíveis de forma semelhante”. (GOFFMAN, [1964] 2002, p. 17)

\footnotetext{
${ }^{12}$ A proposta desse tipo de organização é que não haja hierarquia ou liderança. Cada indivíduo teria autonomia e poder de decisão. Os rumos seriam delineados em conjunto, com participação de todos. Uma ideia que se alinha com a democracia direta, na qual cada indivíduo representa a si próprio e a tomada de deciões se dá por meio de assembleias gerais.

${ }^{13}$ Organizando debates, palestras, exibição de filmes, peças teatrais - tudo o que colaborasse para discussão dos problemas político-econômicos do país.

${ }^{14}$ Um debate que esteve muito presente nas manifestações foi a questão da mídia. Contra a mídia corporativa, acusada de manipular a informação, grupos foram se organizando como mídia alternativa, buscando um caráter mais transparente na divulgação das informações.
} 
Assim, uma situação social torna-se o lugar de acessibilidade, no qual as pessoas monitoram umas às outras. As regras são estabelecidas de acordo com o grupo, com a convivência entre as pessoas e são elas que organizam socialmente o comportamento daqueles que estão presentes na situação.

Concebendo a entrevista como um tipo de interação social, o que ali se diz está intimamente relacionado a toda uma situação - o que se fala, para quem e em qual contexto questões que também permeiam as conversas espontâneas. No caso da interação em análise, os significados construídos entre Rodrigo e eu se entrelaçam no contexto do qual fazemos parte.

Um entendimento adequado acerca das entrevistas depende do reconhecimento de como os entrevistadores reformulam questões e como os participantes (no caso entrevistados) formulam respostas baseadas em seus entendimentos recíprocos dos significados que emergem no curso da entrevista (Mishler, 1986). Sendo que tal significado não é prédeterminado, ele é criado por meio do discurso entre entrevistador e entrevistado, ele não é singular, muito menos fixo, e possibilita a continuidade do sentido daquilo que está sendo dito entre eles (Frias, 2013). Portanto, as minhas perguntas e as respostas de Rodrigo, também se baseiam na forma como significamos a violência policial ao longo da entrevista.

A escolha por uma entrevista semi-estruturada, com perguntas abertas, se deu em função do alinhamento a uma perspectiva construcionista, que concebe entrevistador e entrevistado como colaboradores para a produção de sentidos - significa perceber o entrevistado, não como um mero produtor de respostas, mas como construtor e produtor de sentidos na interação. Nela, ele interpreta e reinterpreta experiências e dados que se configuram nas suas respostas à entrevista. Nesse tipo de perspectiva, o entrevistador deixa de ser aquele que extrai os sentidos da experiência do entrevistado por meio de perguntas habilmente construídas e passa a ser aquele que interage com o entrevistado, que ao participar e colaborar para a construção de sentidos, colabora, também, com a produção do conhecimento (Frias, 2013; Mishler, 1986).

Assim, observar a entrevista como uma interação social permite a análise das identidades que são co-construídas entre Rodrigo e eu no momento da entrevista.

\section{2) $O$ contexto e a construção de significados}

Os significados são construídos ao longo de uma interação por meio do discurso e são contextualizados, isto é, discurso e contexto constituem um ao outro. Ele (o discurso) não se dá apenas em contexto, mas também forma-o e constitui-o (Schiffrin, 1994). Assim, o contexto é construído interacionalmente e é dentro dele próprio, que se encontram os significados, as possíveis explicações pelas quais os indivíduos comportam-se de determinada forma e não de outra. Portanto, o significado de uma interação é situado.

Sobre isso, a teoria socioconstrucionista afirma que os significados são compreendidos como resultado dos processos sociointeracionais nos quais os indivíduos engajam-se para buscarem entendimentos da vida que os cerca (Moita Lopes, 2003). 
Posto isso, o contexto de entrevista no qual a pesquisa se dá é construído por mim e por Rodrigo e está entrelaçado a uma situação macro (das manifestações, ocupações de rua e coletivos de mídia) do qual também participamos. Dessa forma, os significados construídos por nós são situados em nesse macro e ainda demonstram os nossos entendimentos acerca daquilo que vivenciamos nas ruas.

Já que em interações situadas os indivíduos corporificam discursivamente e interacionalmente os contextos, construindo, ainda, significados, é possível observar que além da situacionalidade, o discurso ainda envolve alteridade ${ }^{15}$, ou seja, envolve o Outro.

\section{3) A presença do Outro nos discursos}

Sobre a alteridade e o caráter dialógico do discurso, temos, em Bakhtin, que "nossa fala, isto é, nossos enunciados, estão repletos de palavras dos outros, caracterizadas, em graus variáveis, pela alteridade ou pela assimilação" (2003, p. 314 [grifo de Bakhtin]). Isto significa que todo enunciado constitui um elo numa cadeia infinita de enunciados que vão sendo construídos na medida em que os indivíduos participam de interações. Dessa forma, "as palavras dos outros introduzem sua própria expressividade, seu tom valorativo, que assimilamos, reestruturamos, modificamos" (BAKHTIN, 2003, p. 318) a fim de atribuirmos novos significados a elas em função dos diversos contextos nos quais estamos inseridos.

Bakhtin, na análise dos problemas da poética de Dostoievski ${ }^{16}$ destaca a presença de uma multiplicidade de vozes de consciências independentes e imiscíveis e a autêntica polifonia de vozes plenas de valor. Tais vozes mantêm uma relação de igualdade com as outras vozes do discurso, que ao participarem do diálogo com outras vozes, não se objetificam, não perdem o seu ser enquanto vozes e consciências autônomas (Bakhtin, 1997). A essência da polifonia consiste no fato de que as vozes podem ser ideologicamente distintas, permanecerem independentes e, como tais, combinarem-se numa unidade superior à homofonia.

Com essas considerações, é possível compreender o discurso, não como uma formação que se dá num plano individual, mas como um elo na cadeia de vários discursos, várias vozes que circulam na sociedade. Tal situação se faz presente nesta pesquisa, tendo em vista que a fala de Rodrigo dialoga com os discursos circulantes na sociedade acerca das manifestações de junho.

\footnotetext{
${ }^{15}$ Ideia que será melhor discutida em 3.3.

${ }^{16}$ Bakthin opõe o romance polifônico criado por Dostoiévsk ao romance monológico (tradicional europeu). 


\section{4) A co-construção das identidades na interação}

A identidade pode ser entendida como um "construto central na compreensão das mudanças sociais, políticas, tecnológicas, culturais e econômicas" (MOITA LOPES, 2003, p. 17).

Para Bauman (2005) a identidade é um objetivo, um propósito, não é um fator prédefinido, não é dada ao indivíduo assim que nasce. Sendo assim, precisa ser construída, podendo ainda ser reconstruída, em função da situação à qual o indivíduo se encontra. Possui então, caráter mutável. Tal mutabilidade insere-se no que Bauman (2007) chama de sociedade líquido-moderna, cujas condições, sob as quais agem seus membros, mudam em um tempo mais curto do que aquele necessário para que as formas de agir se consolidem como hábitos e como rotinas. Em uma sociedade desse tipo, as realizações individuais não podem solidificarse em posses permanentes, pois, em pouco tempo, tudo pode mudar. Em tal contexto, um indivíduo passa a ser constituído por múltiplas faces, em função da constante mudança do meio em que vive. Levando isso em consideração, um mesmo indivíduo pode construir inúmeras identidades, de acordo com os ambientes nos quais circula.

Sobre as identidades, Moita Lopes (2003), cita Gee (1990), para quem cada indivíduo é membro de muitos Discursos e cada um desses Discursos representa uma das múltiplas identidades existentes nesses indivíduos. Com isso, a temática das identidades surge em meio a uma concepção discursiva. Como o uso do discurso envolve ação humana com relação a alguém, em algum contexto, isto é, envolve alteridade e situacionalidade ${ }^{17}$, a noção de Discurso envolve indivíduos em algum contexto de produção.

Portanto, a identidade de uma pessoa é construída em sociedade e é o meio social em que esse indivíduo vive e as suas interações sociais que influenciarão a forma como ele se constrói. Tal construto possui caráter dialógico, na medida em que o sujeito se constrói em interações sociais, ele também contribui para a construção da identidade de outros, via discurso.

Dentro da pesquisa, as identidades co-construídas por mim e por Rodrigo, além de serem fruto de nossa interação na entrevista, ainda relacionam-se com o meio social no qual vivemos e com as interações das quais participamos nas ocupações de rua e nos coletivos de mídia alternativa.

Posto o dinamismo das interações e dos contextos nos quais cada indivíduo circula, alguns traços identitários podem se tornar mais relevantes do que outros, o que revela o caráter mutável das identidades (Moita Lopes, 2003). Quando os indivíduos estão diante de uma situação social, buscam expressar uma imagem de si, tentando manipular a expressão que o outro terá (Goffman, [1959] 2008). Posto isso, em nossa interação, Rodrigo e eu tornamos relevantes as identidades que nos constroem numa luz favorável diante da situação que vivenciamos nas lutas na rua.

\footnotetext{
${ }^{17}$ Este termo é utilizado tal qual Moita Lopes (2001) e refere-se à noção de que os discursos dos indivíduos precisam ser investigados nos contextos específicos nos queis estão inseridos.
} 


\section{4) Análise dos dados}

\section{1) Os discursos outros e a construção identitária}

O excerto abaixo faz parte do momento inicial da entrevista, quando eu indago Rodrigo acerca de suas impressões, histórias e sentimentos sobre as ações da polícia. Sua fala expõe suas opiniões a respeito do que ele chama de lógica de atuação da polícia e de que forma tal lógica surpreendeu a população de classe média.

Excerto 1 (00:52) "é a gente num levou tiro de fuzil, a gente levou tiro de borracha"

24

25

26

27

28

29

30

31

32

33

34

35

36

37

38

39

40

41

42

43

44

45

46

47

48

49

50

51

52

53

54

55

56

57

58

59

60

61

62

63

64

65

66

Rodrigo cara, assim, é: eu acho que: >essas manifestações<, elas estão trazendo muita coisa à tona. assim, é: a >atuação da polícia, < ela num acho que ela ficou diferente agora, apenas surgiram novas, novos momentos pra ela atuar. mas a lógica de atuação não mudou e é isso que surpreendeu, porque $\downarrow$ muita gente não, não parava pra racionalizar o que que era realmente políicia e agora a gente tá vendo que: realmente, é: eu >sou da classe média<, assim, então até pouco tempo eu não era um inimigo do estado, >entendeu< eu não, não causava nenhum dano $\downarrow$ e a partir do momento que eu começo a me engajar muito politicamente pra mudar esse estado, eu viro um inimigo. >todo mundo que quer mudar aquilo< ou que não interessa pra especulação imobiliária, pros interesses econômicos daquele estado, que eram os pobres, >não necessariamente a polícia, massacrava os pobres, porque eles se manifestavam< massacrava os pobres, simplesmente porque eles existiam é: o morador de rua sempre foi massacrado, - ambulante sempre foi massacrado, porque naquela lógica de estado, eles eram inimigos pra, pra quaisquer interesses, seja o: de: valorização imobiliá:ria, seja da >realização de grandes eventos< e agora $\uparrow$, pra própria existência desse estado corrupto, eu sou $\downarrow$ é eu passo pro lado dos inimigos, né, todo mundo que tá ali na manifestação, que é uma manifestação muito clara, enfim, >às vezes é muito clarał às vezes não é $\downarrow<$ mas é: é: uma coisa muito mais forte e tem alvos bem direcionados, apesar de acharem, de dizerem que não

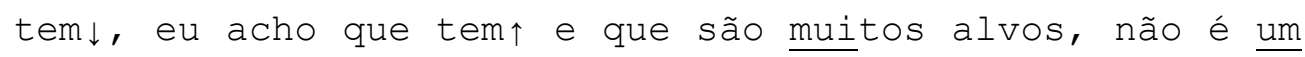
alvo, são, é muitos focos, sabe? é: não falta foco, na verdade tem excesso de foco, até sabe e: e a polícia, ela vem, >exatamente< pra, pra coibir, que algo seja mudado, nessa, né, nesse sentido assim, né, desse

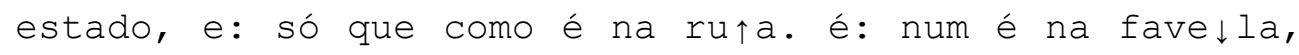
tem gente filmando, tem, então tem certas coisas ali, que são atenuadas assim né, é a gente num levou tiro de fuzil, a gente levou tiro de borracha, a gente num

Revista Escrita

Rua Marquês de São Vicente, 225 Gávea-RJ CEP 22451-900 Brasil

Ano 2014. Número 19. ISSN 1679-6888.

escrita@puc-rio.br 


\begin{abstract}
levou, é: porrada, ninguém foi estuprado no meio da da rua, como acontece quando a polícia entra na >favela< é: e nesse sentido, eu acho que eles têm muita noção do que que tá sendo feito. sół que a lógica é a mesma, a lógica de repressão é a mesma
\end{abstract}

Levando em consideração que nosso discurso é um elo numa cadeia de enunciados construídos na sociedade (Bakhtin, 2003), é possível perceber a presença de discursos outros circulantes na sociedade acerca não só das ações da polícia, mas das manifestações como um todo, no discurso que Rodrigo constrói.

Um discurso que circulou pela mídia quando as reivindicações das manifestações tomaram uma proporção maior do que a redução das tarifas de transporte coletivo foi de que o foco havia se perdido. Quando Rodrigo diz todo mundo que tá ali na manifestação, que é uma manifestação muito clara, enfim, >às vezes é muito clarâ às vezes não é $\downarrow<$ mas é: é: uma coisa muito mais forte e tem alvos bem direcionados, apesar de acharem, de dizerem que não

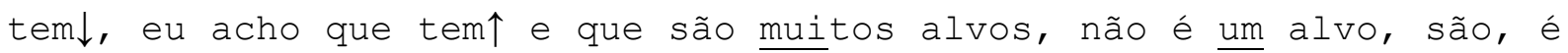
muitos focos, sabe? é: não falta foco, na verdade tem excesso de foco, até (linhas 47 a 55), ele traz esse discurso da mídia, rejeitando-o. Tendo em vista que quando as palavras dos outros introduzem sua própria expressividade e tom valorativo, quando nós as assimilamos, as reestruturamos em nosso discurso, as modificamos (Bakhtin, 1997) ou ainda, nesse caso, rejeitamos. Rodrigo constrói sua argumentação rejeitando esse discurso veiculado pela mídia acerca da falta de foco.

Um outro ponto relevante para análise aqui é o perfil dos manifestantes de junho. Conforme discutido anteriormente, pode-se considerar as pessoas que estavam nas ruas no período estudado como pertencentes a uma classe média elitista. Como pertencentes a essa classe, tais pessoas não estariam acostumadas com o uso da violência policial. No trecho: >essas manifestações<, elas estão trazendo muita coisa à tona. assim, é: a >atuação da polícia,< ela num acho que ela ficou diferente agora, apenas surgiram novas, novos momentos pra ela atuar. mas a lógica de atuação não mudou e é isso que surpreendeu, porque $\downarrow$ muita gente não, não parava pra racionalizar o que que era realmente políłcia e agora a gente tá vendo que: realmente (linhas 24 a 30) Rodrigo levanta essa questão, posto que a polícia aplicou a mesma lógica de atuação utilizada na favela para reprimir a chamada classe média. Sendo tal atuação avaliada por Rodrigo, como um fato surpreendente.

É preciso ainda, observar que circula na sociedade, ainda que de forma invisível, um discurso (Bakhtin, 2003, 1997) de que existe um alvo a quem a repressão deve se dirigir e esse alvo não é a chamada classe média. Rodrigo ratifica isso em: < massacrava os pobres, simplesmente porque eles existiam (linhas 40 e 41) porque naquela lógica de estado, eles eram inimigos pra, pra quaisquer interesses, seja o: de: valorização imobiliá:ria, seja da >realização de 
grandes eventos< e agora个, pra própria existência desse estado corrupto eu sou $\downarrow$ é eu passo pro lado dos inimigos, né, todo mundo que tá ali na manifestação (linhas 42 a 49). Nesse ponto, Rodrigo se encaixaria no grupo de pessoas que não deveria sofrer repressão, no entanto, ao se engajar em movimentos de protesto, ele passa para o lado dos "inimigos" e, assim, acaba sofrendo repressão, tal qual os pobres, conforme ele diz em: >todo mundo que quer mudar aquilo< ou que não interessa pra especulação imobiliária, pros interesses econômicos daquele estado, que eram os pobres, >não necessariamente a polícia, massacrava os pobres, porque eles se manifestavam< massacrava os pobres, simplesmente porque eles existiam é: (linhas 36 a 41).

Rodrigo constrói-se identitariamente ao argumentar que sofreu repressão, porque "passou para o lado dos inimigos do Estado". Sendo as identidades "modos de ser certos tipos de pessoa" (GEE 1990 apud MOITA LOPES 2003), intimamente relacionadas ao contexto social, cada sujeito irá possuir marcas identitárias específicas que o localizam na vida social e que o posicionam no discurso de um modo singular, assim como posicionam também, as pessoas que estão participando da interação (Moita Lopes, 2003).

Apesar de se construir como pertencente à classe média, é: eu >sou da classe média<, assim, então até pouco tempo eu não era um inimigo do estado, >entendeu< eu não, não causava nenhum dano $\downarrow$ e a partir do momento que eu começo a me engajar muito politicamente pra mudar esse estado, eu viro um inimigo (linhas 31 a 35), Rodrigo parece tentar se distanciar dessa classe, tendo em vista o discurso que muito circulou pela sociedade brasileira como um todo ${ }^{18}$ acerca da repressão exagerada aos manifestantes (em função da condição socioeconômica deles). Tal busca é perceptível por meio da polifonia presente em seu discurso. Quando ele traz as múltiplas vozes imiscíveis e ideologicamente contraditórias (Bakhtin, 1997) em seus argumentos, só que como é na ru个a. é: num é na fave $l$ la, tem gente filmando, tem, então tem certas coisas ali, que são atenuadas assim né, é a gente num levou tiro de fuzil, a gente levou tiro de borracha, a gente num levou, é: porrada, ninguém foi estuprado no meio da da rua, como acontece quando a polícia entra na $>$ favela< (linhas 58 a 63) ele as rejeita, se construindo não como um indivíduo de classe média reprimido injustamente, mas como uma pessoa politicamente engajada, que já possuía um entendimento acerca da lógica de atuação da polícia na favela - embora nunca tivesse sofrido algo até então (até virar um inimigo do Estado) por conta dessa lógica só $\uparrow$ que a lógica é a mesma, a lógica de repressão é a mesma (linhas 65 e 66). Tal oposição ao discurso de manifestante classe média pode também estar associada à questão da deslegitimação do movimento, isto é, se a maioria participante do protesto é de uma elite, então suas reivindicações não seriam legítimas como as de pessoas que realmente precisam lutar para garantir seus direitos. Como um indivíduo que embora pertencente à classe média, é engajado politicamente, um discurso desse tipo deslegitimaria a luta de Rodrigo nas ruas.

\footnotetext{
${ }^{18}$ Por meio das redes sociais, principalmente.
} 
Nas interações, os indivíduos, normalmente, buscam se construir numa luz favorável (Goffman, [1959] 2008), levando em consideração que eu (a pesquisadora) participo do mesmo contexto que Rodrigo, isto é, que estive presente às manifestações e circulo nos mesmos discursos e tendo como base que o contexto é interacionalmente construído, assim como os seus significados (Schiffrin, 1994), torna-se positivo em nossa interação se construir como um indivíduo politizado e ativo na luta, em oposição à construção de classe média, que foi reprimida injustamente ao participar de uma manifestação. Até porque, após o esvaziamento das ruas, apenas grupos que se reconheciam como politicamente engajados permaneceram em outras frentes de atuação, o que colabora para reforçar a identidade de ativista.

\section{2) Co-construção de contexto e as construções identitárias}

Esse excerto faz parte da narrativa que Rodrigo conta acerca da prisão arbitrária a que foi submetido em um dos protestos dos quais participou. Aqui, ele expõe não a história em si, mas seus sentimentos e pensamentos no momento em que estava sendo conduzido até a delegacia.

Excerto 2 - (11:42) "eu num matei um monte de gente e cheguei agora e pedi 'sem violência"”

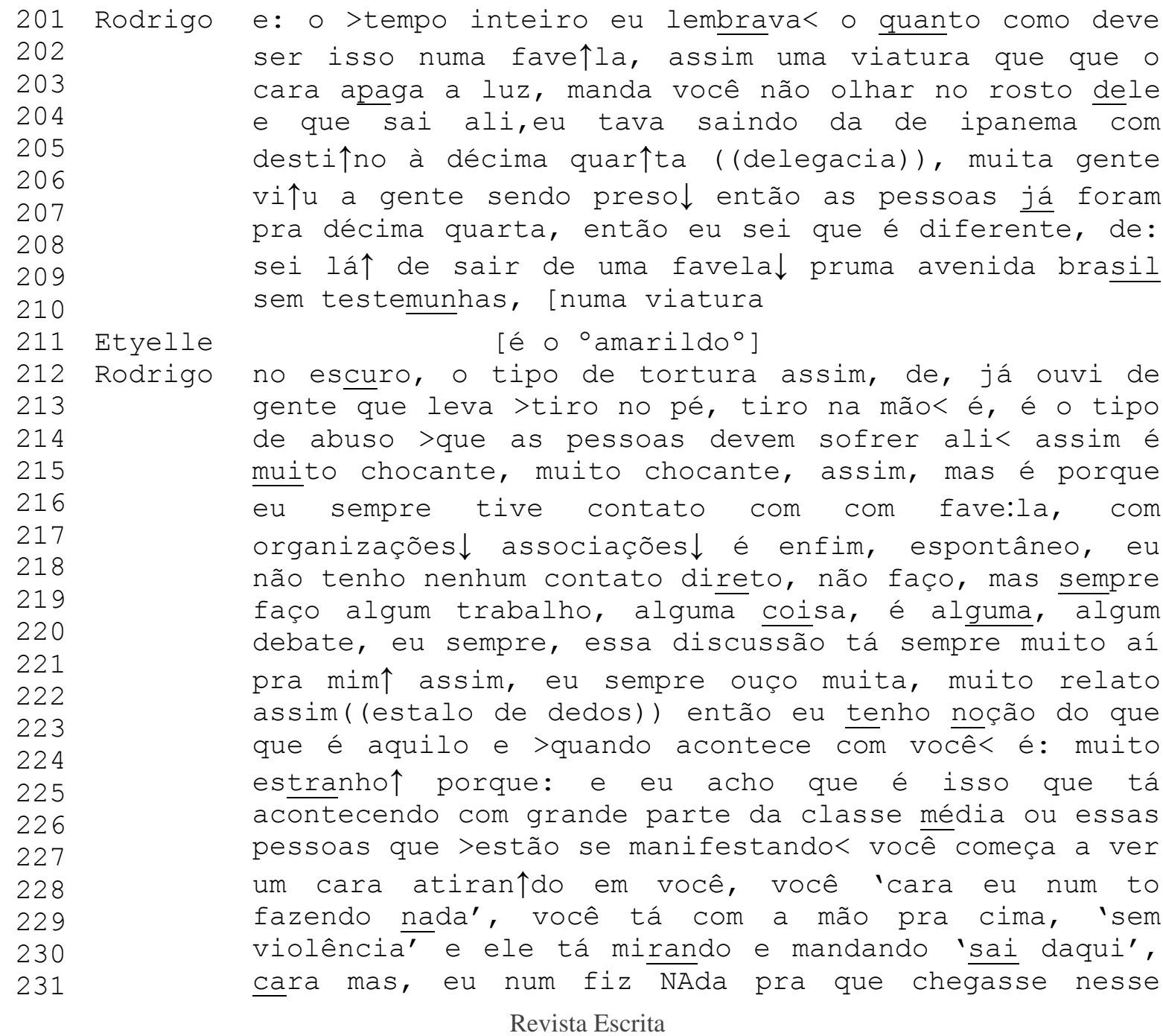




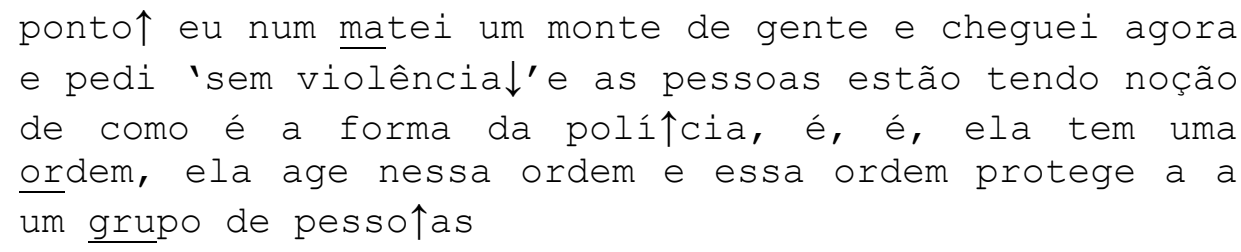

Importante frisar nesse excerto a questão interacional desenhada entre nós. Para a análise desse excerto, vamos levar em consideração as seguintes questões: 'quem é o interlocutor? E quais discursos são permitidos/esperados com esse interlocutor?'

Sendo os significados construídos interacionalmente (Moita Lopes, 2003; Schiffrin, 1994), as falas de Rodrigo em: e: o >tempo inteiro eu lembrava< o quanto como deve ser isso numa fave个la, assim uma viatura que que o cara apaga a luz, manda você não olhar no rosto dele (linhas 201 a 203); no escuro, o tipo de tortura assim, de, já ouvi de gente que leva >tiro no pé, tiro na mão< é, é o tipo de abuso >que as pessoas devem sofrer ali< assim é muito chocante, muito chocante (linhas 212 a 215) só adquirem sentido em função da interação que construímos. Tendo em vista o movimento que Rodrigo faz durante a interação, para se construir numa luz favorável, (Goffman, [1959] 2008) como alguém engajado na luta pelas ruas, ele traz aqui, mais uma face dessa identidade (Bauman, 2007; Moita Lopes, 2003), a de indivíduo que possui compaixão pelo sofrimento do favelado face a uma prisão arbitrária.

Posto que as identidades são construções discursivas, multifacetadas e até contraditórias (Bauman, 2005, 2007; Moita Lopes, 2001, 2003), Rodrigo busca se construir se distanciando da chamada classe média manifestante, em favor de indivíduo politicamente engajado que entende que a repressão que se dá no asfalto é bem menor do que aquela que se dá na favela: essa discussão tá sempre muito aí pra mim个 assim, eu sempre ouço muita, muito relato assim((estalo de dedos)) então eu tenho noção do que que é aquilo e >quando acontece com você< é: muito estranho porque: e eu acho que é isso que tá acontecendo com grande parte da classe média (linhas 221 a 226). Para além da construção de sujeito engajado, Rodrigo também mostra que viveu empiricamente a situação e separa que ouvir um relato é bem diferente de vivenciá-lo: eu sempre ouço muita, muito relato ; >quando acontece com você<. Ele avalia essa situação, fazendo uso do intensificador e do adjetivo: muito estranho个 (linhas 224 e 225).

Eu me alinho à construção de indivíduo engajado politicamente realizada por Rodrigo, demonstrando, não apenas que entendo o que ele está falando, como concordo, fazendo o uso de uma sobreposição em [é o ${ }^{\circ}$ amarildo ${ }^{\circ}$ (linha 210). Levando em consideração que eu, a interlocutora, participo desse contexto, torna-se significativo e até esperado, o fato dele lembrar-se como deve ser uma prisão na favela, enquanto vivenciava a mesma experiência, já que é contra arbitrariedades desse tipo que lutamos também. 
Rodrigo demonstra que está sempre presente, de alguma forma, na favela, o que o constrói como uma pessoa engajada nos movimentos sociais: eu sempre tive contato com com fave:la, com organizações $\downarrow$ associações $\downarrow$ é enfim, espontâneo, eu não tenho nenhum contato direto, não faço, mas sempre faço algum trabalho, alguma coisa, é alguma, algum debate (linhas 216 a 220). Entretanto, é importante notar a forma como ele destaca seu engajamento, que à princípio até parece ser contraditória. Pois ele diz que "sempre teve contato com favela" e depois diz que esse contato não era "direto", mas que "sempre fazia algum trabalho espontâneo", ou seja, seu contato com a favela não era institucionalizado, ele não se coloca como participante de algum movimento social específico, mas como uma pessoa que participa de forma espontânea e indireta. Tal espontaneidade, se configura numa construção numa luz favorável (Goffman, [1959] 2008), posto que mesmo não "tendo contato direto", Rodrigo "sempre faz algum trabalho".

Posto os discursos que circulam (Bakhtin, 2003) acerca da classe social à qual os manifestantes de junho perteceriam, não seria uma construção favorável colocá-los no conjunto de pessoas de classe média. Assim, Rodrigo realiza um auto reparo ao se referir ao que está acontecendo às pessoas que estiveram nas ruas: e eu acho que é isso que tá acontecendo com grande parte da classe média ou essas pessoas que >estão se manifestando< (linhas 225 a 227). Esse auto reparo pode ser percebido com o uso do termo "ou".

Por fim, Rodrigo, ainda busca enfatizar, no trecho a seguir, as medidas exageradas da polícia, frente à uma situação que não envolvia uma prática criminosa: você começa a

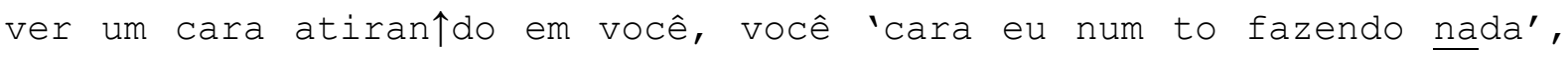
você tá com a mão pra cima, 'sem violência' e ele tá mirando e mandando 'sai daqui', cara ma, eu num fiz NAda pra que chegasse nesse ponto $\uparrow$ eu num matei um monte de gente e cheguei agora e pedi 'sem violência' $\downarrow$ (linhas 228 a 233). Ele reclama a função primeira da polícia, que é punir, penalmente, crimes que são qualificados e típicos do código penal, (como matar um monte de gente) e não, agir com truculência frente à pessoas que, além de "não estarem fazendo nada", ainda, estavam com "a mão pra cima" (um sinal de redenção).

Além de justificar o seu pedido de "sem violência" baseado no fato de não ter feito nada de errado, ele ainda significa as ações da polícia como 'vilã', que independente de qualquer situação (justa ou não) agirá da mesma forma em: ' e as pessoas estão tendo noção de como é a forma da políłcia, é, é, ela tem uma ordem, ela age nessa ordem e essa ordem protege a a um grupo de pesso个as (linhas 233 a 236).

A partir dos dados analisados, foi possível perceber as construções identitárias (Moita Lopes, 2003) do manifestante Rodrigo, como um ativista, diante das ações de repressão da polícia. Ao resgatar discursos Outros (Bakhtin, 1997, 2003) em sua fala, ele busca se construir numa luz favorável (Goffman, [1959] 2008), como um ativista engajado. Ele também 
significa a polícia como "vilã", que faz uso de violência exagerada contra os manifestantes, pessoas que não estão fazendo nada de errado, na visão dele.

\section{Considerações finais}

Por meio das interações as identidades mutáveis e fragmentadas (Bauman, 2005; 2007) dos indivíduos são co-construídas nos e pelos discursos que os envolvem, dos quais fazem parte, isto é, as identidades são práticas discursivas, se dão em sociedade, de forma dialógica (Moita Lopes, 2001, 2003). Esse caráter dialógico se faz presente no discurso, pois a experiência verbal individual das pessoas toma forma e evolui sob o efeito da interação contínua e permanente com os enunciados das outras pessoas (Bakhtin, 1997). Com essas considerações, é possível compreender o discurso não como uma formação que se dá num plano individual, mas como um elo na cadeia de vários discursos, várias vozes -que podem ser ideologicamente contraditórias - que circulam na sociedade.

Iniciamos esse artigo indagando acerca de como os manifestantes constroem significados a respeito da violência da polícia nos protestos e de que forma tais significados colaboram para a construção identitária desses manifestantes. No caso dessa pesquisa, como Rodrigo, constrói-se, em uma entrevista, como um ativista. Com base na análise de dados gerados em situação de entrevista e nos construtos teóricos do socioconstrucionismo do discurso e das identidades, bem como nos conceitos de dialogismo e polifonia, é possível responder às questões colocadas nos seguintes termos:

1) Os significados construídos acerca das ações da polícia são situados em nossa interação (na entrevista) e levam em consideração o contexto macro do qual participamos - protestos, ocupações de rua e reuniões de coletivos de mídia alternativa.

2) Em nossa interação a co-construção identitária de Rodrigo se dá com um discurso dialógico e polifônico, é possível perceber as vozes de discursos como o da mídia em sua fala;

3) Rodrigo tenta construir-se numa luz favorável, opondo-se à manifestante classe média que sofreu com as ações da polícia, em favor de indivíduo politicamente engajado.

Espera-se, com esse estudo, contribuir para os entendimentos acerca das construções identitárias dos indivíduos, observando de que forma os contextos e interações dos quais participam, colaboram para essa construção (Moita Lopes, 2001, 2003), levando em consideração o caráter dialógico e polifônico do discurso (Bakhtin, 1997, 2003).

\section{Bibliografia}

BAKHTIN, M. Problemas da Poética de Dostoievski; trad. Paulo Bezerra. Rio de Janeiro: Forense Universitária, 1997. 
Estética da Criação verbal. São Paulo: Martins Fontes, 2003 - 4ª Edição.

BAUMAM, Z. Identidade: entrevista a Benedetto Vecchi/ Zygmunt Baumam. Rio de Janeiro: Jorge Zahhar, 2005.

Tempos líquidos. Rio de Janeiro: Jorge Zahar Ed., 2007.

CASTELLS, M. Redes de indignação e esperança - Movimentos sociais na era da internet. Rio de Janeiro: Zahar, 2012.

DENZIN, N.; LINCOLN, Y. 2000. The discipline and practice of qualitative research. In: N. DENZIN; Y. LINCOLN (org.), The handbook of qualitative research. Thousand Oaks: Sage, p. 1-27

DUARTE, L. F.; GOMES, E. C. Três famílias: identidades e trajetórias transgeracionais nas classes populares. Rio de Janeiro: Editora FGV, 2008.

FRIAS, M. V. "E aí, presidente, esse cafezinho vai sair?”: entrevista na mídia analisada como performance. In BASTO, L.C.; SANTOS, E. S. Dos. A entrevista na pesquisa qualitativa Perspectivas em análise da narrativa e da interação. Rio de Janeiro: Quartet Editora, 2013.

GOFFMAN, E. A Representação do Eu na Vida Cotidiana. 15. ed. Petrópolis: Ed.Vozes, 2008 [1959]

A situação negligenciada. In RIBEIRO, B. T. e GARCEZ, P. M. (orgs.) Sociolinguística Interacional. São Paulo: Editora Loyola, $2^{\text {a }}$ Edição revista e ampliada, 2002 [1964].

MISHLER, E. G. Research Interviewing. Context and narrative. Cambridge: Harvard University Press, 1986.

MOITA LOPES, L.P. Práticas narrativas como espaço de construção das identidades sociais: uma abordagem socioconstrucionista. In RIBEIRO, LIMA E LOPES DALAI (orgs. Narrativa, Identidade e Clínica. Rio de Janeiro: IPUB, 2001.

Discurso de Identidades. Campinas, SP: Mercado das Letras, 2003.

LODER, L.L. (2008). O modelo Jefferson de transcrição: convenções e debates. In: L.L. LODER; N.M. JUNG (org.) Fala-em-interação social: introdução à análise da conversa etnometodógica, São Paulo: Mercado de Letras, p. 127-161.

OLIVEIRA, T. Educação e ascensão social: performances narrativas de alunos da rede pública federal na Baixada Fluminense. 2012, p. 126. Tese (Estudos da Linguagem) Pontifícia Universidade Católica, Rio de Janeiro.

SCHIFFRIN, D. Approaches to Discourse.Cambridge, Massachusetts, Blackwell Publishers, 1994. 
SINGER, A. Brasil, junho de 2013: Classes e ideologias cruzadas. Novos estud. CEBRAP no.97 São Paulo Nov. 2013 Disponível em: http://www.scielo.br/scielo.php?pid=S010133002013000300003\&script=sci_arttext\&tlng=es Acesso: 13/06/2014

VELHO, G. Individualismo e Cultura: notas para uma Antropologia da Sociedade. Complexa. $8^{\text {a }}$ Ed. Rio de Janeiro: Jorge Zahar Ed. 2008 [1981].

\section{Anexo \\ Convenções de Transcrição Jefferson (cf. Lorder, 2008).}

[ início de sobreposição de fala

] final de sobreposição de fala

$\uparrow$ Som mais agudo dos que os do entorno

$\downarrow$ Som mais grave do que os do entorno

(1.2) Medida de silêncio em segundos e décimos de segundo

${ }^{\circ}$ palavras ${ }^{\circ}$ Som em volume mais baixo dos que os do entorno

(.) silêncio de menos de dois décimos de segundo

$>$ palavras $<$ fala acelerada

$=$ elocuções contíguas

_sublinhado Ênfase em som
. Entonação descendente

MAIÚSCULA Som em volume mais alto do que os do entorno

? Entonação ascendente

, entonação intermediária

<palavras > fala desacelerada

(( )) Descrição de atividade não-vocal

: prolongamento do som

(palavras) transcrição duvidosa

- Corte abrupto na produção vocal

( ) Segmento de fala que não pôde ser transcrito 